\title{
Blood Flow and Glucose Metabolism in Stage IV Breast Cancer: Heterogeneity of Response During Chemotherapy
}

\author{
Nanda Krak, ${ }^{1}$ Jacobus van der Hoeven, ${ }^{2}$ Otto Hoekstra, ${ }^{3}$ Jos Twisk, ${ }^{4}$ \\ Elsken van der Wall, ${ }^{5}$ Adriaan Lammertsma ${ }^{3}$ \\ ${ }^{1}$ Radiology, Erasmus Medical Centre, Rotterdam, The Netherlands \\ ${ }^{2}$ Medical Oncology, Medical Center Alkmaar, Alkmaar, The Netherlands \\ ${ }^{3}$ Nuclear Medicine and PET Research, VU University Medical Center, Amsterdam, The Netherlands \\ ${ }^{4}$ Epidemiology and Biostatistics, VU University Medical Center, Amsterdam, The Netherlands \\ ${ }^{5}$ Medical Oncology, University Medical Center Utrecht, Utrecht, The Netherlands
}

\begin{abstract}
Objective: The purpose of the study was to compare early changes in blood flow (BF) and glucose metabolism $\left(\mathrm{MR}_{\mathrm{glu}}\right)$ in metastatic breast cancer lesions of patients treated with chemotherapy. Methods: Eleven women with stage IV cancer and lesions in breast, lymph nodes, liver, and bone were scanned before treatment and after the first course of chemotherapy. BF, distribution volume of water $\left(V_{\mathrm{d}}\right), \mathrm{MR}_{\mathrm{glu}} / \mathrm{BF}$ ratio, $\mathrm{MR}_{\mathrm{glu}}$ and its corresponding rate constants $K_{1}$ and $k_{3}$ were compared per tumor lesion before and during therapy.

Results: At baseline, mean $\mathrm{BF}$ and $\mathrm{MR}_{\mathrm{glu}}$ varied among different tumor lesions, but mean $V_{\mathrm{d}}$ was comparable in all lesions. After one course of chemotherapy, mean $\mathrm{MR}_{\mathrm{glu}}$ decreased in all lesions. Mean BF decreased in breast and node lesions and increased in bone lesions. $V_{\mathrm{d}}$ decreased in breast and nodes, but did not change in bone lesions. The $M_{\text {glu }} / B F$ ratio decreased in breast and bone lesions and increased in node lesions. In patients with multiple tumor lesions $\mathrm{BF}$ and $\mathrm{MR}_{\text {glu }}$ response could be very heterogeneous, even within similar types of metastases. $\mathrm{BF}$ and $\mathrm{MR}_{\mathrm{glu}}$ increased in lesions of patients who experienced early disease progression or showed no response during clinical follow-up.

Conclusion: $\mathrm{BF}$ and $\mathrm{MR}_{\mathrm{glu}}$ changes separately give unique information on different aspects of tumor response to chemotherapy. Changes in $\mathrm{BF}$ and $\mathrm{MR}_{\text {glu }}$ parameters can be remarkably heterogeneous in patients with multiple lesions.
\end{abstract}

Key words: Positron emission tomography, Blood flow, Glucose metabolism, Breast cancer, Metastases

\section{Introduction}

T tage IV breast cancer is considered incurable. Treatment $\checkmark$ is directed towards palliation of symptoms and disease stabilization, and with the use of polychemotherapy and taxanes, overall survival can be prolonged [1-2]. Conven-

Correspondence to: Nanda Krak; e-mail: n.krak@erasmusmc.nl tionally, clinical response is evaluated after several cycles of chemotherapy by monitoring changes in tumor dimension as determined by physical examination and (anatomical) imaging techniques. There are certain tumor-specific characteristics that play a role in responsiveness to therapy. For example, high glucose metabolism and high degree of (neo) vascularization correlate with poor prognosis, and vascularization and perfusion are important factors in growth and 
metastasizing potential of breast tumors [3-5]. On the other hand, poor tumor perfusion may hamper delivery of intravenous therapy and may lead to hypoxia, which is known to contribute to resistance to standard radiotherapy and chemotherapy and is associated with poor prognosis [67]. Overall clinical response rates following chemotherapy, as measured conventionally, vary between $20 \%$ and $80 \%$, depending on the (combination of) agent used $[2,8]$. This means that many patients are exposed to the morbidity, side effects, and costs of ineffective therapy. There is evidence that measurement of metabolic changes using positron emission tomography (PET) might be a sensitive method to assess early response to treatment [9-13]. The ultimate goal of using PET would be to guide effective treatment to responders, while avoiding unnecessary side effects in nonresponders.

To date, most PET studies in breast cancer assessing response have involved patients with locally advanced breast cancer (LABC) [9-15], and only a few focused on metastatic breast cancer [16-18]. The change emphasizes response assessment. At present, the most commonly used tracer in response monitoring studies is the glucose analogue 2deoxy-2-[F-18]fluoro-D-glucose (FDG), which measures glucose metabolism. An alternative approach is to measure tumor perfusion in vivo using $\mathrm{H}_{2}{ }^{15} \mathrm{O}$, a freely diffusible, metabolically inert tracer [18]. Both FDG and $\mathrm{H}_{2}{ }^{15} \mathrm{O}$ could provide, either by themselves or combined, better insight into tumor behavior both prior to and during chemotherapy, e.g., by identifying factors that may play a role in responsiveness [13, 14, 19].

Thus, the primary aim of this pilot study was to compare early changes in blood flow (BF) and glucose metabolism $\left(\mathrm{MR}_{\mathrm{glu}}\right)$ in metastatic breast cancer lesions of patients treated with chemotherapy.

\section{Materials and Methods}

\section{Patients}

Eleven patients with stage IV breast cancer who were scheduled to receive chemotherapy were included in this study. Mean age \pm SD was $55 \pm 9$ years (range $42-72$ years). All patients had an Eastern Cooperative Oncology Group (ECOG) performance status ranging from $0-2$. Metastases were at least $2 \mathrm{~cm}$ in diameter and located sufficiently near the heart to make use of an image-derived arterial input function. Metastases were biopsy proven or diagnosed by appropriate image modalities (bone scan, abdominal ultrasound, or abdominal CT). Bone metastases were characterized as lytic, blastic, or mixed based on their appearance on X-ray or CT. Exclusion criteria were pregnancy, diabetes, claustrophobia, and chemotherapy within 6 weeks prior to the study. In addition, bone lesions that had received prior selective radiotherapy were excluded as reference lesions.

PET scans were performed within 5 days before the first and second course of chemotherapy, respectively. Regimens included FAC (5-fluorouracil $500 \mathrm{mg} / \mathrm{m}^{2}$, cyclophosphamid $500 \mathrm{mg} / \mathrm{m}^{2}$, and doxorubicin $50 \mathrm{mg} / \mathrm{m}^{2}$ 3-weekly), Doc (docetaxel $100 \mathrm{mg} / \mathrm{m}^{2} 3$ weekly), AT (doxorubicin $50 \mathrm{mg} / \mathrm{m}^{2}$ and docetaxel $100 \mathrm{mg} / \mathrm{m}^{2} 3-$ weekly), CAT (cisplatinum $50 \mathrm{mg} / \mathrm{m}^{2}$, doxorubicin $50 \mathrm{mg} / \mathrm{m}^{2}$, paclitaxel $100 \mathrm{mg} / \mathrm{m}^{2}$ 3-weekly), and Vinorelbine $\left(25 \mathrm{mg} / \mathrm{m}^{2}\right.$ weekly). The Medical Ethics Committees of the VU University Medical Centre and Amstelland Hospital approved the study.

\section{Tumor Response and Clinical Follow-Up}

Referring physicians were blinded to results of the second PET scan. After the second PET scan, patients returned to regular follow-up with their treating physician. Clinical endpoint was time to progression (TTP). Disease progression was defined by the treating physician, as directed by symptoms, blood tests, and/or physical examination during follow-up using appropriate imaging modalities, i.e., ultrasound or CT for liver lesions and bone scan, CT, or MRI for bone lesions. Progression of lymph nodes and liver metastases was defined by the RECIST criteria [20]. For bone metastases, any increase in size of known metastases or the appearance of new metastases was interpreted as progression.

\section{Acquisition Protocol and Image Processing}

All PET scans were performed on an ECAT EXACT HR+ scanner (Siemens/CTI, Knoxville, TN, USA), which consists of 32 rings of bismuth germinate crystal detectors and has a $15.5-\mathrm{cm}$ axial field of view. Patients fasted for at least $6 \mathrm{~h}$ prior to scanning. Following a 10-min transmission scan to correct the subsequent emission scans for photon attenuation, $1,100 \mathrm{MBq}$ of $\mathrm{H}_{2}{ }^{15} \mathrm{O}$ was injected intravenously, simultaneously starting a 10 -min dynamic emission scan $(12 \times 5 \mathrm{~s}, 12 \times 10 \mathrm{~s}, 6 \times 20 \mathrm{~s}$ and $10 \times 30 \mathrm{~s}$ frames $)$. Next, a second dynamic emission scan with a total duration of $60.5 \mathrm{~min}$ $(1 \times 30 \mathrm{~s}, 6 \times 5 \mathrm{~s}, 6 \times 10 \mathrm{~s}, 3 \times 20 \mathrm{~s}, 5 \times 30 \mathrm{~s}, 5 \times 60 \mathrm{~s}, 8 \times 150 \mathrm{~s}, 6 \times$ $300 \mathrm{~s}$ frames) was started, with an intravenous injection of $370 \mathrm{MBq}$ of FDG at the start of the second frame. The $30 \mathrm{~s}$ background frame was used to correct for any residual ${ }^{15} \mathrm{O}$ activity remaining from the $\mathrm{H}_{2}{ }^{15} \mathrm{O}$ scan. All data were acquired in $2 \mathrm{D}$ mode. During the FDG scan venous samples were collected at 35 , 45, and 55 min postinjection for measurement of plasma glucose and for quality control of the image-derived input function [21]. All PET data were corrected for decay, dead time, scatter, random coincidences, and measured photon attenuation. All scans were reconstructed as $128 \times 128$ matrices using filtered back projection (FBP) with a 0.5 Hanning filter, resulting in a transaxial spatial resolution of $\sim 7 \mathrm{~mm}$ in the centre of the field of view. For definition of tumor regions of interest (ROIs), summed images of the FDG scan and $\mathrm{H}_{2}{ }^{15} \mathrm{O}$ scan were reconstructed using ordered subset expectation maximization (OSEM), which was followed by $5 \mathrm{~mm}$ Gaussian smoothing, resulting in the same transaxial spatial resolution as for the FBP images [22].

\section{PET Data Analysis}

Arterial input curves were derived from $15 \mathrm{~mm}$ ROIs placed over the aorta, left atrium, and left ventricle [23], using the FBP images of the fourth and fifth frames for the FDG scan [24] and the first 12 frames for the $\mathrm{H}_{2}{ }^{15} \mathrm{O}$ scan [25].

All tumor ROIs were defined on OSEM reconstructed images of the FDG scan. These ROIs were used to generate time-activity curves from the dynamic frames of both the FDG and $\mathrm{H}_{2}{ }^{15} \mathrm{O}$ scans. ROIs were drawn using a semiautomatic region-growing method, including only pixels with a cutoff of $75 \%$ of the maximum activity within a lesion [26]. 
For $\mathrm{H}_{2}{ }^{15} \mathrm{O}$, the standard single-tissue compartment model was used [18]. Blood flow (BF) was not calculated for liver lesions because estimates using the single-tissue compartment model may not be reliable for the liver [27]. Fitting was performed both with and without an arterial blood volume component, and the best fit was determined by Akaike and Schwarz criteria, as described previously [24].

For FDG, Patlak graphical analysis [28] with an acquisition interval of 10-60 min p.i. was used to calculate glucose metabolism $\left(\mathrm{MR}_{\mathrm{glu}}\right)$. The two-tissue compartment model with three rate constants [24, 29] was used in addition, in order to acquire more detailed information on delivery $\left(K_{1}\right)$ and phosphorylation $\left(k_{3}\right)$ of FDG.

Finally, the $\mathrm{MR}_{\mathrm{glu}}$ to $\mathrm{BF}$ ratio was calculated, a metabolic parameter introduced by Mankoff et al. as an indirect indicator of glucose use relative to glucose delivery and used as a predictor of macroscopic complete response [13]. This ratio is proportional to $K_{1} / \mathrm{BF}$ (= glucose extraction fraction) $\times k_{3} /\left(k_{2}+k_{3}\right)$.

\section{Statistics}

For all lesions, mean \pm standard deviation (SD) was calculated for $\mathrm{MR}_{\text {glu }}$, rate constants $K_{1}$ and $k_{3}, \mathrm{BF}, V_{\mathrm{d}}$, and $\mathrm{MR}_{\mathrm{glu}} / \mathrm{BF}$ before treatment and after one course of chemotherapy. Differences in parameters before and after chemotherapy were tested for significance using the two-tailed Student $t$-test. Pearson correlation coefficients were estimated between $\mathrm{BF}$ and $\mathrm{MR}_{\text {glu }}$, between $\mathrm{BF}$, $K_{1}$, and $k_{3}$, and between the MRglu/BF ratio, $K_{1}$ and $k_{3}$, both before and during treatment. Multilevel analysis was performed to correct for multiple lesions within the same patient. A $p$ value $<0.05$ was considered statistically significant.

\section{Results}

\section{Baseline}

All patients were scanned twice (at baseline and after one course of therapy) with FDG and $\mathrm{H}_{2}{ }^{15} \mathrm{O}$, with the exception of one patient for whom $\mathrm{H}_{2}{ }^{15} \mathrm{O}$ was not available on the second scan for technical reasons. The same number of lesions was identified on the FDG and $\mathrm{H}_{2}{ }^{15} \mathrm{O}$ scans. Uptake was adequate (moderate to high) in baseline lesions, so no conventional imaging was necessary to help identify these lesions. On the baseline scans, 45 measurable lesions were found: eight breast tumors, 17 lymph nodes, 15 bone, and five liver metastases. Lymph node metastases included axillary and supraclavicular nodes. The median follow-up period was 13 months. Patient characteristics are summarized in Table 1.

Baseline $\mathrm{MR}_{\mathrm{glu}}$ in normal breast was $0.01 \pm 0.004 \mu \mathrm{mol} \cdot \mathrm{ml}^{-1}$. $\min ^{-1}$ vs. $0.11 \pm 0.07 \mu \mathrm{mol} \cdot \mathrm{ml}^{-1} \cdot \mathrm{min}^{-1}$ in breast tumors $(p<$ 0.03). $\mathrm{MR}_{\mathrm{glu}}$ was comparable in breast tumors and lymph node metastases, and higher in bone and liver metastases (Table 2). BF and $V_{\mathrm{d}}$ values used in this study were estimated without an arterial blood volume component, as both Akaike and Schwarz criteria indicated that inclusion of arterial blood volume did not significantly improve the quality of the fits. Normal breast had a mean baseline BF of $0.04 \pm 0.03$ vs. $0.43 \pm 0.23 \mathrm{ml} \cdot \mathrm{ml}^{-1} \cdot \mathrm{min}^{-1}$ in breast tumors $(p<0.02)$. Mean BF was highest in node metastases $(0.60 \pm$ $\left.0.27 \mathrm{ml} \cdot \mathrm{ml}^{-1} \cdot \mathrm{min}^{-1}\right)$ and lowest in bone lesions $(0.41 \pm$ $\left.0.24 \mathrm{ml} \cdot \mathrm{ml}^{-1} \cdot \mathrm{min}^{-1}\right) . V_{\mathrm{d}}$ was $0.13 \pm 0.06 \mathrm{ml} \cdot \mathrm{ml}^{-1}$ in normal breast tissue. $V_{\mathrm{d}}$ values in breast lesions were similar to those in nodal and bone lesions. The $\mathrm{MR}_{\mathrm{glu}} / \mathrm{BF}$ ratio was lowest in node lesions $(0.23 \pm 0.15)$, followed by breast tumors $(0.31 \pm 0.19)$ and bone lesions $(0.41 \pm 0.29)$.

\section{Chemotherapy-Induced Changes}

The same 45 baseline lesions were identified on the FDG scans after one course of therapy. One patient with bilateral breast lesions and ten node metastases could only be scanned with FDG the second time, however, so 33 lesions were evaluable on the post-therapy $\mathrm{H}_{2}{ }^{15} \mathrm{O}$ scans of ten women: six breast tumors, seven lymph nodes, 15 bone, and five liver metastases.

After one cycle of chemotherapy, mean $\mathrm{MR}_{\mathrm{glu}}$ decreased in all lesions. Compared with baseline, these reductions were statistically significant for breast tumors, nodes, and bone lesions and of borderline significance for liver lesions (see Table 2).

Mean BF decreased in all lesions except bone metastases (Table 2 and Fig. 1a). Mean $\underline{V}_{\mathrm{d}}$ decreased in breast tumors

Table 1. Patient characteristics

\begin{tabular}{|c|c|c|c|c|c|c|}
\hline Patient no. & Age & Histology & Tumor lesions & Therapy & TTP (months) & TTD (months) \\
\hline 1 & 72 & Ductal & Bone (lytic) & FAC & 6 & 9 \\
\hline 2 & 42 & Lobular & Liver & Vino & 11 & 14 \\
\hline 3 & 47 & Ductal & Supraclavicular nodes & Doc & 2 & 2 \\
\hline 4 & 42 & Adeno & Liver & Doc & 5 & 20 \\
\hline 5 & 53 & Lobular & Breast $^{\mathrm{a}}$, axillary nodes & $\mathrm{AT}$ & 4 & 5 \\
\hline 6 & 58 & Adeno & Breast, bone (mixed) & CAT & NER & NER \\
\hline 7 & 65 & Lobular & Breast $^{\mathrm{b}}$, supraclavicular nodes & FAC & 5 & 6 \\
\hline 8 & 55 & Lobular & Breast, axillary nodes, bone (mixed) & Vino & 4 & 26 \\
\hline 9 & 59 & Adeno & Breast, cervical nodes, bone (sclerotic) & FAC & 12 & 24 \\
\hline 10 & 49 & Ductal & Breast, axillary nodes, bone (lytic), liver & Doc & 4 & 13 \\
\hline 11 & 58 & Ductal & bone (mixed) & FAC & 9 & 13 \\
\hline
\end{tabular}

TTP Time to progression, TTD time till death, NER no evidence of recurrence, ductal ductal carcinoma, lobular lobular carcinoma, adeno adenocarcinoma, $F A C$ 5-fluorouracil, cyclophosphamid, doxorubicin, Doc docetaxel, AT doxorubicin, docetaxel, CAT cisplatinum, doxorubicin, paclitaxel, Vino Vinorelbine aultifocal tumor

${ }^{\mathrm{b}}$ Bilateral tumor 
Table 2. PET parameters before and after one course of chemotherapy for normal breast and tumor lesions

\begin{tabular}{|c|c|c|c|}
\hline Parameter & Baseline mean $( \pm \mathrm{SD})$ & After $1 \times$ CTh mean $( \pm \mathrm{SD})$ & $p$ \\
\hline \multicolumn{4}{|c|}{$\mathrm{MR}_{\mathrm{glu}}(\mu \mathrm{mol} / \mathrm{ml} / \mathrm{min})$} \\
\hline Normal breast & $0.01 \pm 0.004$ & $0.01 \pm 0.004$ & 0.97 \\
\hline Breast tumor & $0.11 \pm 0.07$ & $0.07 \pm 0.04$ & 0.002 \\
\hline Nodes & $0.11 \pm 0.04$ & $0.06 \pm 0.06$ & $<0.001$ \\
\hline Bone metastases & $0.15 \pm 0.10$ & $0.12 \pm 0.09$ & 0.003 \\
\hline Liver metastases & $0.19 \pm 0.09$ & $0.11 \pm 0.04$ & 0.06 \\
\hline \multicolumn{4}{|l|}{$K_{1}(\mathrm{ml} / \mathrm{ml} / \mathrm{min})$} \\
\hline Normal breast & $0.02 \pm 0.01$ & $0.02 \pm 0.01$ & 0.59 \\
\hline Breast tumor & $0.11 \pm 0.05$ & $0.13 \pm 0.07$ & 0.41 \\
\hline Nodes & $0.18 \pm 0.09$ & $0.13 \pm 0.12$ & 0.23 \\
\hline Bone metastases & $0.16 \pm 0.08$ & $0.24 \pm 0.13$ & 0.25 \\
\hline Liver metastases & $0.26 \pm 0.20$ & $0.25 \pm 0.10$ & 0.26 \\
\hline \multicolumn{4}{|l|}{$K_{3}\left(\min ^{-1}\right)$} \\
\hline Normal breast & $0.02 \pm 0.01$ & $0.01 \pm 0.01$ & 0.42 \\
\hline Breast tumor & $0.05 \pm 0.03$ & $0.03 \pm 0.02$ & 0.05 \\
\hline Nodes & $0.07 \pm 0.04$ & $0.05 \pm 0.02$ & 0.11 \\
\hline Bone metastases & $0.06 \pm 0.04$ & $0.05 \pm 0.03$ & 0.18 \\
\hline Liver metastases & $0.10 \pm 0.09$ & $0.03 \pm 0.02$ & 0.11 \\
\hline \multicolumn{4}{|l|}{$\mathrm{BF}(\mathrm{ml} / \mathrm{ml} / \mathrm{min})$} \\
\hline Normal breast & $0.04 \pm 0.03$ & $0.04 \pm 0.02$ & 0.88 \\
\hline Breast tumor & $0.43 \pm 0.23$ & $0.35 \pm 0.15$ & 0.09 \\
\hline Nodes & $0.60 \pm 0.27$ & $0.21 \pm 0.17$ & 0.15 \\
\hline Bone metastases & $0.41 \pm 0.24$ & $0.51 \pm 0.29$ & 0.26 \\
\hline \multicolumn{4}{|l|}{$V_{\mathrm{d}}(\mathrm{ml} / \mathrm{ml})$} \\
\hline Normal breast & $0.13 \pm 0.06$ & $0.10 \pm 0.07$ & 0.95 \\
\hline Breast tumor & $0.69 \pm 0.17$ & $0.63 \pm 0.28$ & 0.29 \\
\hline Nodes & $0.73 \pm 0.19$ & $0.54 \pm 0.29$ & 0.17 \\
\hline Bone metastases & $0.67 \pm 0.21$ & $0.67 \pm 0.30$ & 0.77 \\
\hline \multicolumn{4}{|c|}{$\mathrm{MR}_{\mathrm{glu}} / \mathrm{BF}(\mu \mathrm{mol} / \mathrm{ml})$} \\
\hline Normal breast & $0.17 \pm 0.16$ & $0.14 \pm 0.08$ & 0.75 \\
\hline Breast tumor & $0.31 \pm 0.19$ & $0.21 \pm 0.03$ & 0.06 \\
\hline Nodes & $0.23 \pm 0.15$ & $0.32 \pm 0.21$ & 0.79 \\
\hline Bone metastases & $0.41 \pm 0.29$ & $0.26 \pm 0.15$ & 0.05 \\
\hline
\end{tabular}

$S D$ Standard deviation, $C T h$ chemotherapy

and nodes and remained unchanged in bone lesions (Fig. 1b). Compared with baseline, however, changes in $\mathrm{BF}$ and $V_{\mathrm{d}}$ were not statistically significant (Table 2).

There was an increase in $K_{1}$ in breast tumors and bone lesions and a decrease in nodes and liver lesions, while $k_{3}$ decreased in all lesions. Except for the decrease in $k_{3}$ in breast lesions $(p<0.05)$, changes in $K_{1}$ and $k_{3}$ were not statistically significant in other lesions.

Changes in the $\mathrm{MR}_{\mathrm{glu}} / \mathrm{BF}$ ratio were only significant for bone lesions $(p<0.05)$, although they approached significance for breast tumors $(p=0.06)$.

\section{Correlation Between Parameters}

Correlation between baseline $\mathrm{MR}_{\mathrm{glu}}$ and $\mathrm{BF}$ was moderate for breast lesions ( $r=0.79$, Fig. 2 and Table 3), and even lower for nodes and bone metastases ( $r=0.64$ and 0.49 , respectively). Excluding the 12 lesions from the patient with bilateral breast lesions and ten node metastases that did not receive the second $\mathrm{H}_{2}{ }^{15} \mathrm{O}$ scan from the baseline, analysis resulted in only moderately lower correlation values $(r=0.76$ and $r=0.51$ for breast and nodes, respectively). After therapy, correlation between $\mathrm{MR}_{\mathrm{glu}}$ and $\mathrm{BF}$ improved dramatically for breast lesions $(r=0.98)$, but remained similar for nodes and bone metastases ( $r=0.62$ and $r=0.50$, respectively).

At baseline, correlation between $\mathrm{BF}$ and $K_{1}$ or $\mathrm{BF}$ and $k_{3}$ was weak to moderate for breast lesions $(r=0.43$ and $r=0.58$, respectively), but after chemotherapy, there was a significant improvement in correlation ( $r=0.86, p<0.03$ and $r=0.94, p<$ 0.005 , respectively). In contrast, in bone lesions, correlation between BF and $K_{1}$ was similar before and after therapy ( $r=$ 0.62 and $r=0.59$, respectively), while the modest baseline correlation between $\mathrm{BF}$ and $k_{3}(r=0.52)$ was lost after therapy $(r=0.15)$. Because of the small number of lymph nodes after therapy, changes in correlation between $\mathrm{BF}$ and $\mathrm{MR}_{\mathrm{glu}}$ parameters should be viewed with caution (see Table 3).

\section{Inter-lesion Heterogeneity}

Changes in $\mathrm{BF}$ and $\mathrm{MR}_{\mathrm{glu}}$ after the first course of chemotherapy were often remarkably heterogeneous within one patient, not only between different types of lesions, but even within similar lesions. Fig. 3 shows examples of typical heterogeneous response in two patients with multiple lesions. Similarly, heterogeneous response was observed in patient nos. 6,8 , and 10 . 

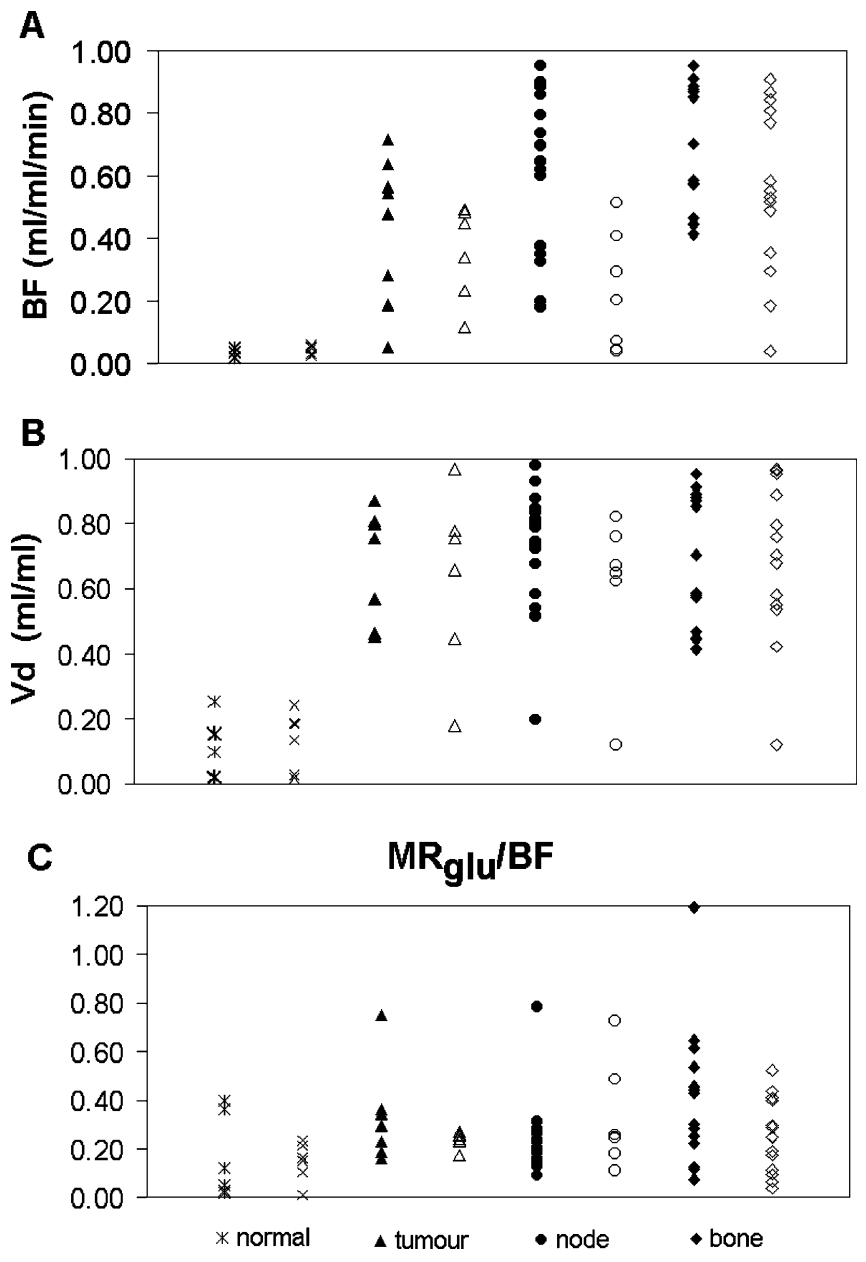

Fig. 1. BF (a), Vd (b), and MRglu/BF (c) at baseline (bold symbols) and after one course of chemotherapy (open symbols) for normal breast and (metastatic) breast cancer lesions.

\section{PET Parameters vs. Clinical Outcome}

Because ten of 11 patients showed disease progression during clinical follow-up, patients were subdivided further into those that showed early disease progression (TTP $\geqq$ 6 months) vs. those with late (TTP $>6$ months) or no progression. Seven patients showed early disease progression. In three patients, TTP was longer than 6 months, and one patient was still in clinical remission at the end of follow-up.

Mean $\mathrm{MR}_{\mathrm{glu}} / \mathrm{BF}$ was lower in patients with late or no progression than in patients with early progression $(0.24 \pm$ 0.11 vs. $0.34 \pm 0.21)$, but this difference was not statistically significant $(p=0.21)$. Similarly, differences between baseline and post-therapy values of $\mathrm{BF}, \mathrm{MR}_{\mathrm{glu}}$, and $V_{\mathrm{d}}$ in patients with early progression vs. patients with late or no progression were not statistically significant (data not shown).

When assessed on a lesion basis (Fig. 4), however, $\mathrm{MR}_{\mathrm{glu}}$ and $\mathrm{BF}$ increased only in lesions of patients who progressed early. In contrast, no increase in $\mathrm{MR}_{\text {glu }}$ and $\mathrm{BF}$ was seen in any lesion of patients with TTP $>6$ months. In these patients, $\mathrm{MR}_{\mathrm{glu}}$ and $\mathrm{BF}$ decreased $-32 \% \pm 21 \%$ (range $-8 \%$ to $-69 \%$ ) and $-22 \% \pm 19 \%$ (range $-6 \%$ to $-60 \%$ ), respectively. No predictive pattern as to the occurrence of progression could be found in changes in $V_{\mathrm{d}}$ or $\mathrm{MR}_{\mathrm{glu}} / \mathrm{BF}$ (Fig. 4).

\section{Discussion}

The primary aim of this pilot study was to compare early chemotherapy-induced changes in blood flow and in glucose metabolism in metastatic breast cancer lesions.

The present study is, to our knowledge, the first to report $\mathrm{BF}$ and $V_{\mathrm{d}}$ values for regional and distant breast cancer metastases. Baseline $\mathrm{MR}_{\mathrm{glu}}, \mathrm{BF}$, and $\mathrm{V}_{\mathrm{d}}$ were different among different tumor lesions. $\mathrm{MR}_{\mathrm{glu}}$ and the associated microparameters $K_{1}$ and $k_{3}$ were highest in liver metastases. $\mathrm{MR}_{\mathrm{glu}}$ was lowest (and similar) in breast and node lesions. Baseline BF values were comparable in breast and bone lesions, and on average higher in nodes. In contrast, $V_{\mathrm{d}}$ was comparable among all three lesions.

Mean $\mathrm{BF}$ values in breast tumors were higher than previously reported in patients with (locally advanced) breast cancer, namely, $0.43 \pm 0.23 \mathrm{ml} \cdot \mathrm{ml}^{-1} \cdot \mathrm{min}^{-1}$ in the present study vs. $0.32 \mathrm{ml} \cdot \mathrm{ml}^{-1} \cdot \mathrm{min}^{-1}[13]$ and $0.30 \mathrm{ml} \cdot \mathrm{ml}^{-1} \cdot \mathrm{min}^{-1}$ [18] in two earlier studies. Interestingly, Wilson et al. [18] did report a mean tumor BF of $0.42 \mathrm{ml} \cdot \mathrm{ml}^{-1} \cdot \mathrm{min}^{-1}$ in a subset of patients with Mx or M1 disease, comparable with values in the present study, and higher than values in their patients with M0 disease $\left(0.24 \mathrm{ml} \cdot \mathrm{ml}^{-1} \cdot \mathrm{min}^{-1}\right)$. It is known that tumor growth, progression, and metastagenicity require angiogenesis [30, 31]. In fact, microvessel density has been shown to be significantly higher in breast tumors of patients with metastases, than in those without [32]. The reason for the higher BF values in breast tumors of patients with metastatic disease could be due to this phenomenon, signifying a change in tumor biology (higher vascularization) associated with increased metastatic potential. With a mean value of $0.41 \pm 0.24 \mathrm{ml} \cdot \mathrm{ml}^{-1} \cdot \mathrm{min}^{-1}, \mathrm{BF}$ in bone lesions was much higher than that reported for normal bone marrow, namely, $0.11-0.18 \mathrm{ml} \cdot \mathrm{ml}^{-1} \cdot \mathrm{min}^{-1}[33]$.

After chemotherapy, correlation between $\mathrm{BF}$ and $\mathrm{MR}_{\mathrm{glu}}$ increased dramatically for breast lesions, while in bone lesions, correlation was similar before and after therapy. In breast lesions, both $k_{3}$ and $K_{1}$ contributed to this improvement in correlation, since both showed a significantly higher correlation with $\mathrm{BF}$ after therapy, although this was more pronounced for $k_{3}(r=0.94$ vs. $r=0.83$, Table 3$)$. This is partly confirmed by the study by Tseng et al. [34] involving chemotherapy-treated LABC patients, who suggested that the phosphorylation step $\left(k_{3}\right)$ was responsible for the improved correlation they observed after chemotherapy.

$\mathrm{BF}$ and $K_{1}$ did not correlate well before therapy (Table 3), in contrast to findings of Zasadny et al. [19] and Tseng et al. [34]. Both proposed that BF could possibly be replaced by $K_{1}$, at least for some aspects of metabolic analyses. Although correlation between $\mathrm{BF}$ and $K_{1}$ improved after chemotherapy 

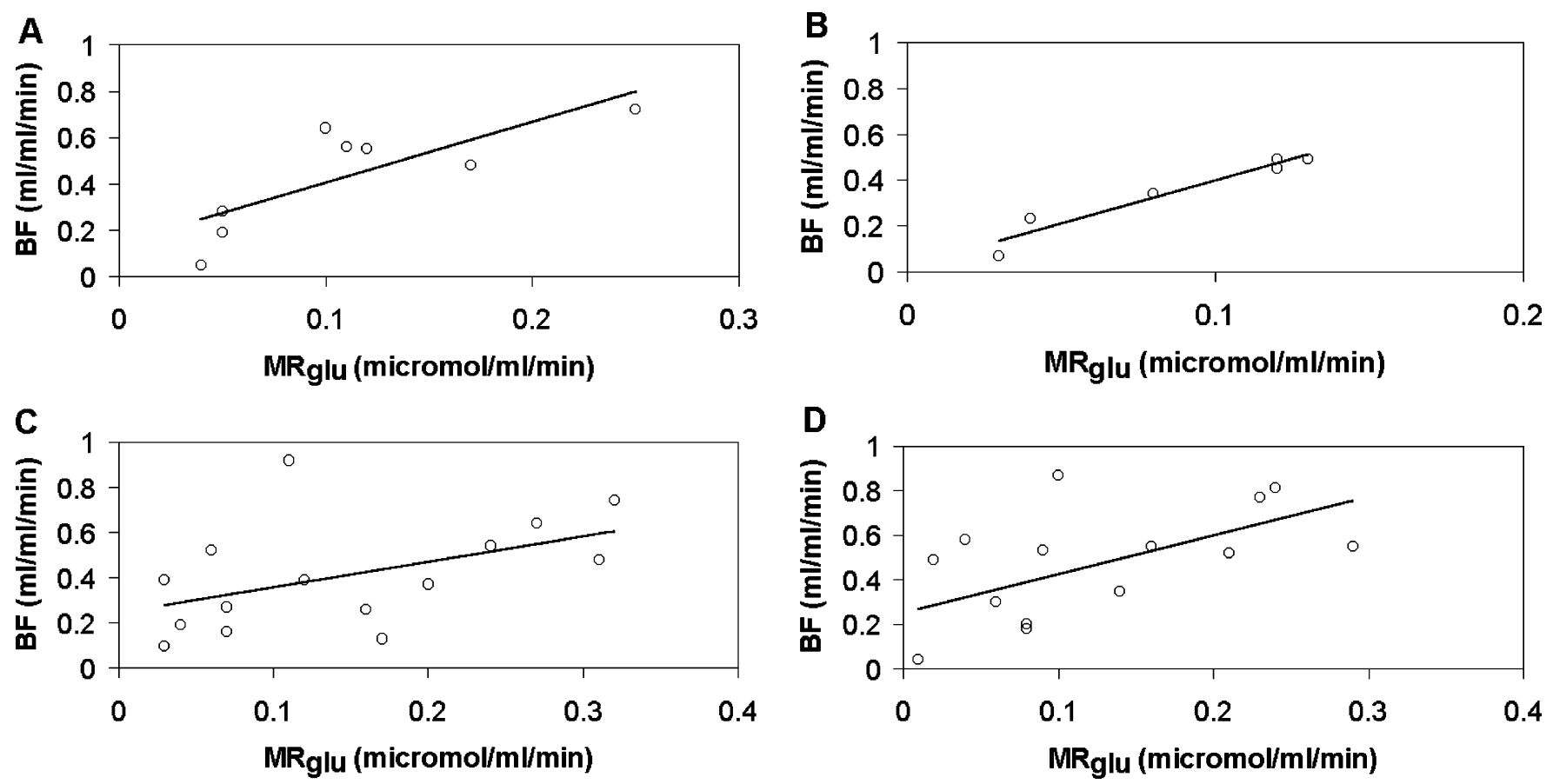

Fig. 2. Correlation between MRglu and BF for breast (a and $\mathbf{b})$ and bone (c and $\mathbf{d})$ lesions before (a and $\mathbf{c})$ and after (b and $\mathbf{d})$ one course of chemotherapy.

in the present study (Table 3), as in Tseng et al. [34], it seems that with the unexplained variance between $\mathrm{BF}$ and $K_{1}$ found in both studies, BF cannot be reliably replaced by $K_{1}$.

$V_{\mathrm{d}}$ reflects the amount of tumor tissue that rapidly exchanges water with blood within the time of the $\mathrm{H}_{2}{ }^{15} \mathrm{O}$ scan [18], and it has been suggested that this represents the proportion of viable tissue within a tumor [35]. If chemotherapy leads to hypo- or hyperperfusion, it will cause a decrease or increase, respectively, in perfusion, but no change in blood volume and $V_{\mathrm{d}}$. If therapy causes vascular shutdown, this would lead to a reduction in all three parameters [35]. In breast tumors and nodes, both BF and $V_{\mathrm{d}}$ decreased after therapy, although to different degrees (Table 2). This could mean that chemotherapy results in

Table 3. Correlation coefficients between $\mathrm{BF}, \mathrm{MR}_{\mathrm{glu}} / \mathrm{BF}$ and microparameters before and after one course of chemotherapy

\begin{tabular}{lllll}
\hline Parameters & Before CTh $(r)$ & $p$ & After CTh $(r)$ & $p$ \\
\hline Breast tumor & & & & \\
BF and $\mathrm{MR}_{\text {glu }}$ & 0.79 & 0.02 & 0.98 & 0.001 \\
$\mathrm{BF}$ and $K_{1}$ & 0.43 & 0.29 & 0.86 & 0.03 \\
$\mathrm{BF}$ and $k_{3}$ & 0.23 & 0.58 & 0.94 & 0.005 \\
Node & & & & \\
$\mathrm{BF}$ and $\mathrm{MR}_{\text {glu }}$ & 0.64 & 0.005 & $0.62^{\mathrm{a}}$ & 0.14 \\
$\mathrm{BF}$ and $K_{1}$ & 0.28 & 0.26 & $0.63^{\mathrm{a}}$ & 0.13 \\
$\mathrm{BF}$ and $k_{3}$ & 0.61 & 0.01 & $0.14^{\mathrm{a}}$ & 0.77 \\
Bone & & & & \\
$\mathrm{BF}$ and $\mathrm{MR}_{\text {glu }}$ & 0.49 & 0.06 & 0.50 & 0.06 \\
$\mathrm{BF}$ and $K_{1}$ & 0.62 & 0.03 & 0.59 & 0.02 \\
$\mathrm{BF}$ and $k_{3}$ & 0.52 & 0.04 & 0.15 & 0.59 \\
\hline
\end{tabular}

${ }^{\mathrm{a} O n l y}$ seven nodes could be compared on both ${ }^{18} \mathrm{FDG}$ and $\mathrm{H}_{2}{ }^{15} \mathrm{O}$ scans after chemotherapy; see text. some degree of vascular shutdown in these lesions. $V_{\mathrm{d}}$ is also very low in normal breast tissue, however, (see Fig. 1b) so an alternative explanation for the lower $V_{\mathrm{d}}$ in breast tumors after chemotherapy could be that values (partially) return to normal. In contrast, mean BF increased in bone lesions, while $V_{\mathrm{d}}$ remained unchanged. Therefore, chemotherapy apparently caused some hyperperfusion in bone metastases.

Mankoff et al. [13] first introduced the $\mathrm{MR}_{\mathrm{glu}} / \mathrm{BF}$ ratio as a parameter that could predict complete response in LABC patients and suggested that a high ratio indicates high glucose extraction. In fact, this ratio is more complex, as it is proportional to glucose extraction fraction times $k_{3} /\left(k_{2}+\right.$ $\left.k_{3}\right)$. In theory, tumors can increase glucose extraction as a survival mechanism under conditions of hypoxia or hypoperfusion [36]. In the present study, the $\mathrm{MR}_{\mathrm{glu}} / \mathrm{BF}$ ratio of patients with late (TTP $>6$ months) or no progressive disease was indeed lower than in those with early progression, but differences were not statistically significant.

The heterogeneity of response observed in this patient group is of particular interest (see Fig. 3). Obviously, BF and $\mathrm{MR}_{\text {glu }}$ represent two separate physiological processes that are not necessarily linked. The heterogeneity in some (responding) bone lesions might partly be explained by the so-called 'osteoblastic flare' phenomenon [37], a paradoxical increase in tracer uptake after successful response of osteolytic metastases due to greater radioisotope uptake by the healing bone. However, the heterogeneous response was also seen in patients without bone metastases. More importantly, an increase in either $\mathrm{BF}$ or $\mathrm{MR}_{\mathrm{glu}}$ in any lesion appeared to be an adverse prognostic sign, regardless of other, well-responding lesions in the same patient. Mankoff 
A
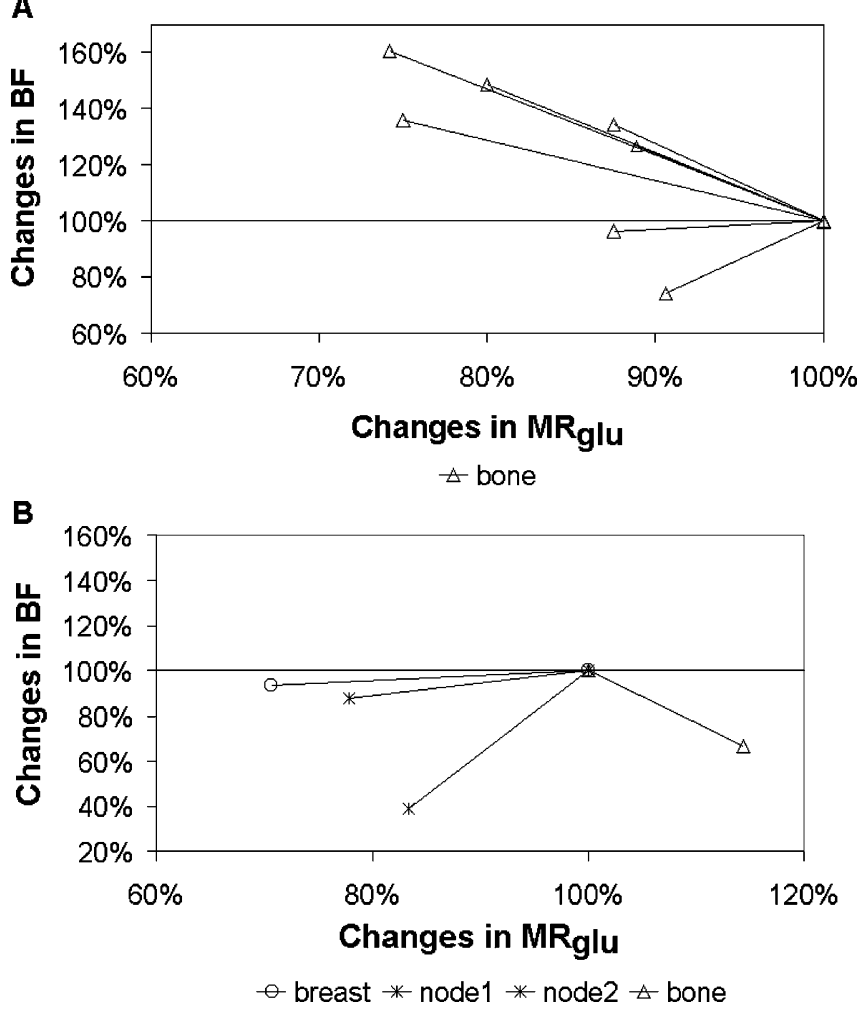

Fig. 3. Two examples of heterogeneous response in patient no. 1 with bone lesions only (a) and in patient no. 9 with breast tumor, nodes, and bone metastases (b). MRglu and BF post-chemotherapy are expressed relative to a baseline value of $100 \%$.

et al. [14] also found an average rise in BF after 2 months of chemotherapy in LABC patients who were classified as clinical or pathological nonresponders. This could mean that an early increase in either $\mathrm{BF}$ or $\mathrm{MR}_{\mathrm{glu}}$ during chemotherapy could be used to identify patients who will not respond to therapy or are at risk for early disease progression. Thirdly, there are potential implications for the design of future PETresponse monitoring studies involving stage IV breast cancer patients. Conventionally, according to the RECIST classification [20] often used to measure tumor response, only a limited number of 'measurable' target lesions are selected at baseline (five per organ, ten in total) and used for subsequent response evaluation. In the light of possible heterogeneous metabolic response, however, it may be more prudent to include and follow-up as many target lesions as possible (within a selected field of view) in order to get a representative view of the overall tumor response in a patient. Bone metastases are considered 'nonmeasurable' by the RECIST criteria [20], but both the present study and that of Stafford et al. [17] suggest that serial quantification of response in bone metastases is possible. Moreover, there is some evidence that ${ }^{18}$ FDG PET can differentiate between 'active' and clinically stable bone metastases [38], that PET is superior (to bone scintigraphy) in detecting osteolytic bone lesions $[39,40]$ and that survival in patients with osteolytic lesions is shorter [40]. As such, uniquely, FDG PET avidity may be an indirect sign of clinical aggressiveness of bone metastases.

This study has a number of limitations. Firstly, the number of patients was small, and there was variability in tumor load and treatment. For example, docetaxel and paclitaxel have known anti-angiogenic effects and would obviously have a different effect on blood flow compared to non-anti-angiogenic agents. This could partly explain the inter-patient response heterogeneity as discussed above, but does not explain the heterogeneous response observed within several individual patients.

The purpose of the study was not to investigate the effects of a specific chemotherapeutic agent on blood flow and glucose metabolism, however, but to investigate whether blood flow and glucose metabolism behave differently under influence of chemotherapy. This was the reason for including therapies with different mechanisms of action. Secondly, selection of metastases was restricted by the axial field of view of the scanner and limited to lesions in the vicinity of the heart in order to make use of image-derived arterial input functions. Thus, in some cases, total tumor load was larger than could be evaluated with this dynamic scanning protocol.

\section{Conclusion}

Simultaneous measurement of changes in tumor perfusion and glucose metabolism in metastatic breast cancer lesions during chemotherapy offers the possibility to study different biological aspects of tumor response to treatment. Chemotherapy-induced changes in blood flow and glucose metabolism can be markedly heterogeneous even between similar lesions in the same patient.

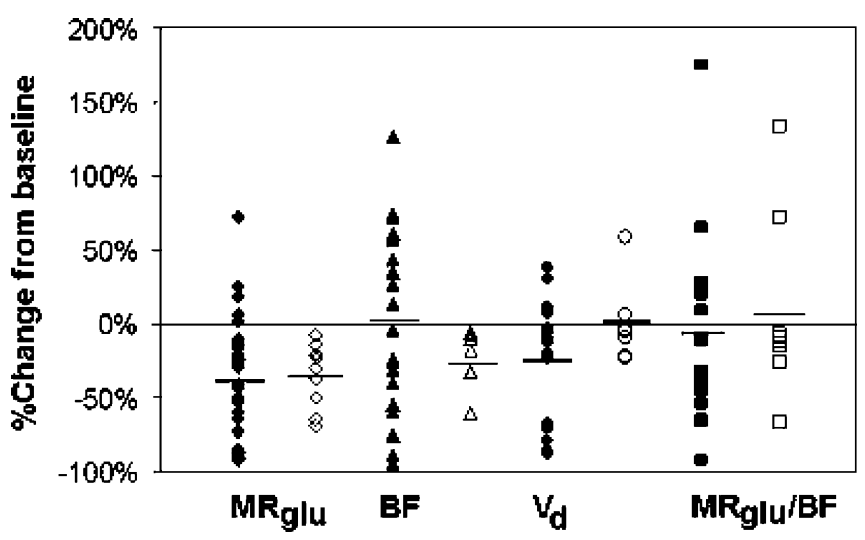

Fig. 4. Percentual changes in MRglu, BF, Vd, and MRglu/BF ratio for all lesions compared to baseline. Patients with early disease progression (TTP $\geqq 6$ months, closed symbols) vs. late or no progression (open symbols). 
Acknowledgement. The authors would like to thank Dr. Johan Nuyts from the Department of Nuclear Medicine, University Hospital Gasthuisberg, Leuven, Belgium, for providing the semiautomatic program that was used to draw the three-dimensional regions of interest.

Open Access. This article is distributed under the terms of the Creative Commons Attribution Noncommercial License which permits any noncommercial use, distribution, and reproduction in any medium, provided the original author(s) and source are credited.

\section{References}

1. Ghersi D, Wilcken N, Simes RJ (2005) A systematic review of taxanecontaining regimens for metastatic breast cancer. Br J Cancer 93:293301

2. Bergh J, Jönsson P-E, Glimelius B et al (2001) A systematic overview of chemotherapy effects in breast cancer. Acta Oncol 40:253-281

3. Oshida M, Uno K, Suzuki M et al (1998) Predicting the prognoses of breast carcinoma patients with positron emission tomography using 2deoxy-2-fluoro[18F]-D-glucose. Cancer 82:2227-2234

4. Uzzan B, Nicolas P, Cucherat M et al (2004) Microvessel density as a prognostic factor in women with breast cancer: a systematic review of the literature and meta-analysis. Cancer Res 64:2941-2955

5. Folkman J (2002) Role of angiogenesis in tumor growth and metastasis. Semin Oncol 29:15-18

6. Dales JP, Garcia S, Meunier-Carpentier S et al (2005) Overexpression of hypoxia-inducible factor HIF-1alpha predicts early relapse in breast cancer: retrospective study in a series of 745 patients. Int J Cancer $116: 734-739$

7. Bos R, van der Groep P, Greijer AE et al (2003) Levels of hypoxiainducible factor-1alpha independently predict prognosis in patients with lymph node negative breast carcinoma. Cancer 97:1573-1581

8. Esteva FJ, Valero V, Pusztai L et al (2001) Chemotherapy of metastatic breast cancer: what to expect in 2001 and beyond. Oncologist 6:133-146

9. Jansson T, Westlin JE, Ahlstrom et al (1995) Positron emission tomography studies in patients with locally advanced and/or metastatic breast cancer: a method for early therapy evaluation? J Clin Oncol 13:1470-1477

10. Bassa P, Kim EE, Inoue $\mathrm{T}$ et al (1996) Evaluation of preoperative chemotherapy using PET with fluorine-18-fluorodeoxyglucose in breast cancer. J Nucl Med. 37:931-938

11. Smith IC, Welch AE, Hutcheon AW et al (2000) Positron emission tomography using [(18)F]-fluorodeoxy-D-glucose to predict the pathologic response of breast cancer to primary chemotherapy. J Clin Oncol 18:1676-1688

12. Schelling M, Avril N, Nahrig J et al (2000) Positron emission tomography using [(18)F]Fluorodeoxyglucose for monitoring primary chemotherapy in breast cancer. J Clin Oncol 18:1689-1695

13. Mankoff DA, Dunnwald LK, Gralow JR et al (2002) Blood flow and metabolism in locally advanced breast cancer: relationship to response to therapy. J Nucl Med 43:500-509

14. Mankoff DA, Dunnwald LK, Gralow JR et al (2003) Changes in blood flow and metabolism in locally advanced breast cancer treated with neoadjuvant chemotherapy. J Nucl Med 44:1806-1814

15. Wahl RL, Zasadny K, Helvie M et al (1993) Metabolic monitoring of breast cancer chemohormonotherapy using positron emission tomography: initial evaluation. J Clin Oncol 11:2101-2111

16. Gennari A, Donati S, Salvadori B et al (2000) Role of 2-[18F]fluorodeoxyglucose (FDG) positron emission tomography (PET) in the early assessment of response to chemotherapy in metastatic breast cancer patients. Clin Breast Cancer 1:156-163

17. Stafford SE, Gralow JR, Schubert EK et al (2002) Use of serial FDG PET to measure the response of bone-dominant breast cancer to therapy. Acad Radiol 9:913-921

18. Wilson CB, Lammertsma AA, McKenzie CG et al (1992) Measurements of blood flow and exchanging water space in breast tumors using positron emission tomography: a rapid and noninvasive dynamic method. Cancer Res 52:1592-1597

19. Zasadny KR, Tatsumi M, Wahl RL (2003) FDG metabolism and uptake versus blood flow in women with untreated primary breast cancers. Eur J Nucl Med Mol Imaging 30:274-280

20. Therasse P, Arbuck SG, Eisenhauer EA et al (2000) New guidelines to evaluate the response to treatment in solid tumors. J Natl Cancer Inst 92:205-216

21. Hoekstra C, Hoekstra O, Lammertsma AA (1999) On the use of image derived input functions in oncological FDG PET studies. Eur J Nucl Med 26:1489-1492

22. Boellaard R, van Lingen A, Lammertsma AA (2001) Experimental and clinical evaluation of iterative reconstruction (OSEM) in dynamic PET: quantitative characteristics and effects on kinetic modeling. J Nucl Med 42:808-817

23. Van der Weerdt AP, Klein LJ, Boellaard R et al (2001) Image-derived input functions for determination of MRglu in cardiac 18F-FDG PET scans. J Nucl Med 42:1622-1629

24. Krak NC, van der Hoeven JJ, Hoekstra O et al (2003) Measuring [(18) F]FDG uptake in breast cancer during chemotherapy: comparison of analytical methods. Eur J Nucl Med Mol Imaging 30:674-681

25. Hoekstra CJ, Stroobants SG, Hoekstra OS et al (2002) Measurement of perfusion in stage IIIA-N2 non-small cell lung cancer using $\mathrm{H}(2)(15) \mathrm{O}$ and positron emission tomography. Clin Cancer Res 8:2109-2115

26. Krak NC, Boellaard R, Hoekstra OS et al (2005) Effects of ROI definition and reconstruction method on quantitative outcome and applicability in a response monitoring trial. Eur J Nucl Med Mol Imaging 32:294-301

27. Ziegler SI, Haberkorn U, Byrne H et al (1996) Measurement of liver blood flow using oxygen-15 labelled water and dynamic positron emission tomography: limitations of model description. Eur J Nucl Med 23:169-177

28. Patlak CS, Blasberg RG, Fenstermacher JD (1983) Graphical evaluation of blood-to-brain transfer constants from multiple- time uptake data. J Cereb Blood Flow Metab 3:1-7

29. Phelps ME, Huang SC, Hoffman EJ (1979) Tomographic measurement of local cerebral glucose metabolic rate in humans with (F-18)2-fluoro2-deoxy-D-glucose: validation of method. Ann Neurol 6:371-388

30. Brown NS, Bicknell R (2001) Hypoxia and oxidative stress in breast cancer. Oxidative stress: its effects on the growth, metastatic potential and response to therapy of breast cancer. Breast Cancer Res 3:323-327

31. Heimann R, Hellman S (2000) Individual characterisation of the metastatic capacity of human breast carcinoma. Eur J Cancer 36:1631-1639

32. Weidner N, Semple JP, Welch WR et al (1991) Tumor angiogenesis and metastasis - correlation in invasive breast carcinoma. N Engl J Med $324: 1-8$

33. Kahn D, Weiner GJ, Ben-Haim S et al (1994) Positron emission tomographic measurement of bone marrow blood flow to the pelvis and lumbar vertebrae in young normal adults. Blood 83:958-963

34. Tseng J, Dunnwald LK, Schubert EK et al (2004) 18F-FDG kinetics in locally advanced breast cancer: correlation with tumor blood flow and changes in response to neoadjuvant chemotherapy. J Nucl Med 45:18291837

35. Anderson H, Price P (2002) Clinical measurement of blood flow in tumours using positron emission tomography: a review. Nucl Med Commun 23:131-138

36. Semenza GL, Roth PH, Fang HM et al (1994) Transcriptional regulation of genes encoding glycolytic enzymes by hypoxia inducible factor 1. J Biol Chem 269:23757-23763

37. Hamaoka T, Madewell JE, Podoloff DA et al (2004) Bone imaging in metastatic breast cancer. J Clin Oncol 22:2942-2953

38. Morris MJ, Akhurst T, Osman I et al (2002) Fluorinated deoxyglucose positron emission tomography imaging in progressive metastatic prostate cancer. Urology. 59:913-918

39. Nakai T, Okuyama C, Kubota T et al (2005) Pitfalls of FDG-PET for the diagnosis of osteoblastic bone metastases in patients with breast cancer. Eur J Nucl Med Mol Imaging 32:1253-1258

40. Cook GJ, Houston S, Rubens R et al (1998) Detection of bone metastases in breast cancer by 18FDG PET: differing metabolic activity in osteoblastic and osteolytic lesions. J Clin Oncol 16:3375-3379 